\title{
PEDOFILIA CIBERNETICA
}

Alessandra Francisca da Silva Mendes, Renata Serra de Oliveira

Universidade do Oeste Paulista - UNOESTE, curso de Direito, Presidente Prudente, SP. E-mail:

alemendes1@ @hotmail.com; renata_serra02@hotmail.com

\section{RESUMO}

Busca-se através deste trabalho tecer comentários sobre a pedofilia gerada através da internet e seus detalhes, desde sua base histórica até os meios de penalidade previstos em decorrência desse ato. Com o passar dos anos, surgiram novos meios, novas técnicas utilizadas pelos criminosos, que se avançam cada vez de forma mais significativa, passando à frente das leis. Esse avanço rápido dos crimes cibernéticos causa a falta de punições, pois sempre surgem técnicas mais avançadas que faz com que os criminosos sejam encontrados com muita dificuldade (em alguns casos, não são encontrados), deixando as vítimas a mercê da falta de reparo dos danos físicos e psicológicos causados a elas.

Palavras-chave: Pedofilia. Internet. Cibernético. Tecnologia. Crianças/Adolescentes.

\section{CIBERNETIC PEDOPHYSIOLOGY}

\section{ABSTRACT}

It is aimed through this work to develop a discussion about pedophilia and its details generated through internet, from its history to the means of penalty established as a consequence to this act. As the years went by, new means and techniques used by the criminals emerged and have been advanced even more significantly, overtaking the laws. This fast advance of the cyber crimes implicates the lack of punishment, for there always are new techniques more advanced that makes it more difficult to find the criminals (some cases, they are not found), leaving the victims at the mercy of the lack of the physical and psychological damage repair caused to them. Keywords: Pedophilia. Internet. Cybernetic. Technology. Children/Adolescent.

\section{INTRODUÇÃO}

O estudo abordado traz à tona uma reflexão sobre um meio de comunicação que vem se inserindo significativamente no cotidiano.

A internet a cada dia que passa torna-se mais indispensável para grande parte da população mundial, com ela é possível pesquisar, trabalhar e até mesmo "namorar." Todavia, muitos criminosos estão aproveitando-se dessa tecnologia para suas práticas delituosas com intuito de tirar proveito de outros internautas que à utiliza.

O grande problema desses delitos cibernéticos é a pouca legislação e impunidade do Estado que não consegue acompanhar os avanços dos crimes por estarem ainda em fase de aprimoramento, causando assim, um incentivo a mais aos criminosos.

A lentidão do poder legislativo vem criando uma imagem de que a internet é uma "Terra sem lei," onde tudo é permitido, tudo é lícito. A identificação dos criminosos na maioria dos casos é tida como impossível, e mesmo quando são identificados, o poder judiciário também apresenta lentidão causando assim, a sensação de impunidade.

\section{METODOLOGIA}


O presente trabalho seguirá os métodos dialético-dedutivo, para cumprir o objetivo proposto, com emprego de pesquisa à legislação, doutrina e jurisprudência acerca da matéria objeto do estudo.

\section{A PEDOFILIA}

De origem grega, a palavra pedofilia significa: "amar ou gostar de crianças". De acordo com alguns estudiosos, o termo pedófilo surge no final do século XIX, em referência à atração de adultos por crianças ou à prática efetiva de sexo com meninos ou meninas.

Na Grécia Antiga, a prática era aceita como cerimônia religiosa, pedagógica, magia e medicina, onde a prática sexual entre uma pessoa mais velha e um jovem, era encarada de forma natural pela família destes adolescentes. Funcionava com a iniciação do jovem à fase adulta, o jovem de sexo masculino era iniciado sexualmente por um homem mais velho.

"Pedofilia é um distúrbio de conduta sexual, onde o indivíduo adulto sente desejo compulsivo, e caráter homossexual (quando envolve meninos) ou heterossexual (quando envolve meninas), por crianças ou pré-adolescentes (...) NOGUEIRA, Sandro D'Amato (20/junho/2003).

"Confunde-se muito o crime de abuso sexual com a pedofilia. A pedofilia é um diagnóstico de atos de crimes. O sujeito pode ser um pedófilo e nunca chegar a encostar a mão em uma criança".

Detalha a psicóloga ESBER, Karen Michel (10/agosto/2010) em "Entenda as diferenças entre pedofilia e crime sexual": Consta na Classificação Internacional de Doenças e Problemas Relacionados à Saúde, que a pedofilia diz respeito aos transtornos de personalidade causados pela preferência sexual por crianças e adolescentes.

\section{PERFIL DO AGRESSOR}

Uma pesquisa realizada com 305 adolescentes molestadores, foram constatados sinais de isolamento e sérios problemas de relacionamentos sociais - 32\% não tinham amigos e 34\% eram mais isolados do que os outros adolescentes não molestadores sexuais e eram cronicamente violentos

A maioria dos pedófilos são homens, e sua atuação é facilitada pelo difícil reconhecimento dos mesmos, pois aparentam ser pessoas comuns, com as quais podemos conviver socialmente sem notar nada de anormal nas suas atitudes.

O distúrbio ocorre na maioria dos casos em homens de personalidade tímida, que se sentem impotentes e incapazes de obter satisfação sexual com mulheres adultas. Muitos casos são de homens casados, insatisfeitos sexualmente.

"Deve-se notar que não há necessidade da presença do ato sexual entre pedófilo e criança, eis que uma pessoa poderá, perfeitamente, ser considerada clinicamente como pedófila apenas pela presença de fantasias ou desejos sexuais em sua mente (...)" CASTRO, Joelíria Vey e BULAWSKI, Cláudio Maldaner -" O Perfil do Pedófilo: Uma Abordagem da Realidade Brasileira".

Seu comportamento não levanta qualquer suspeita pois agem de forma minuciosa para conquistar a confiança e amizade das crianças aproveitando-se de sua inocência e ingenuidade.

Existe a crença de que o agressor sexual atua de acordo com fortes e incontroláveis impulsos e desejos sexuais, ao que explica a genérica para esse crime.

"O abuso sexual infantil é definido como a exposição de uma criança a estímulos sexuais impróprios para a sua idade, onde o adulto ou adolescente mais velho submete a vítima, com ou sem o seu consentimento, a satisfazer ou estimular seus desejos sexuais, impondo pela força física, ameaça, sedução com palavras ou ofertas de presente". ARAÚJO, Naira (2004) - "Abuso e exploração sexual contra crianças e adolescentes". 


\section{O ATO}

Existem diversos crimes praticados no mundo virtual, a pedofilia entretanto, é o que provoca maior revolta e indignação na sociedade e a maioria de seus casos se inicia na internet.

Os pedófilos costumam usá-la pela facilidade que ela oferece para encontrarem suas vítimas. Nas salas de bate-papo ou redes sociais eles utilizam de um perfil falso e usam a linguagem que mais atrai as crianças e adolescentes.

Usam informações fornecidas inocentemente pela própria criança para construir a imagem com que vão se apresentar a ela (como temas de interesse, por exemplo), buscando assim cativar sua atenção; Podem convencer a criança a ligar sua webcam, para conseguir fotografá-la e filmá-la.

Os criminosos se passam por crianças para enganá-las, as prometem presentes, dinheiro, conseguem informações pessoais das crianças e alguns chegam a marcar encontros onde ocorre a agressão física, que começa com um pedido à criança para que retire sua roupa e pode terminar com a morte da vítima.

"Algumas atividades pedofóbicas costumam vir camufladas de brincadeiras ou jogos, muito dos quais implicam toques em 'situações de faz de conta', como brincar de médico, ou de fazer uma dança erótica." TRINDADE e BREIER (2009).

Muitas adolescentes entram nesse "jogo" da sala de bate-papo, onde começam com simples conversas, aos poucos surge a afinidade e então uma relação via web sem saber que do outro lado da tela está um agressor.

Acreditando que estejam conversando e se relacionando com algum garoto de sua idade, a vítima se entrega às belas palavras de encanto e passa a ter confiança no suposto garoto, contando detalhes íntimos de sua vida pessoa.

A confiança adquirida pelo pedófilo abre uma nova porta para sua ação doentia, então, iniciam-se seus pedidos eróticos que são atendidos de forma ingênua pela sua vítima, que passa a enviar fotos ou vídeos em que a mesma aparece despida.

É marcado então o encontro. Muitas das vítimas são surpreendidas inesperadamente pelo agressor, não havendo tempo para a escapatória, mas também, existem as que mesmo descobrindo a verdadeira idade do agressor - acreditando estarem apaixonadas - continuam seu encontro e só percebem a "má intenção" quando o ato do abuso se inicia com agressões e atitudes forçadas.

“(...) Por um ato ou jogo sexual, em uma relação heterossexual ou homossexual, entre um ou mais adultos e uma criança ou adolescente, tendo por finalidade estimular sexualmente esta criança ou adolescente, ou utilizá-la para obter uma estimulação sexual sobre sua pessoa ou de outra pessoa" (AZEVEDO, 1998).

$\mathrm{O}$ ato pode ser evitado por programas de informática que monitoram as atividades das crianças na rede, mas devem ser acompanhados por um diálogo dentro da família, caso contrário, o filho pode acabar se voltando contra os pais e buscando o acesso à internet em lan houses.

\section{CONSEQUÊNCIAS}

O constrangimento em que são expostas as vítimas desse tipo de barbárie tira de uma criança seu bem mais valioso, sua inocência e infância.

"Diversos estudos demonstram que as consequências do abuso sexual infanto-juvenil estão presentes em todos os aspectos da condição humana, deixando marcas - físicas, psíquicas, sociais, sexuais, entre outras - que poderão comprometer seriamente a vida da vítima (criança ou adolescente) que passou por determinada violência". KAPLAN e SADOCK (1990).

Essa violência causa um trauma que traz graves consequências para seu desenvolvimento físico, psíquico, emocional e em seu poder de aprendizagem. 
As crianças e adolescentes que às sofreram, passam a ter maior dificuldade de aprendizagem, sofrem de insônia, tem pesadelos, fobias de contatos e até mesmo passam a rejeitar carinhos, são retraídas, se tornam agressivas, tímidas, deprimidas, impacientes, desconfiadas, entre outros problemas.

\section{PUNIÇÃO}

“Embora não sendo a pedofilia tipificada como crime, aqueles diagnosticados pedófilos, que praticam determinadas condutas para satisfazer seus desejos sexuais, cometem crimes previstos no Código Penal (CP) e no Estatuto da Criança e do Adolescente (ECA)". COUTINHO, Isadora Caroline Coelho - "Pedofilia na Era Digital". O crime de estupro consiste no fato de o agente "constranger alguém, mediante violência ou grave ameaça, a ter conjunção carnal ou a praticar ou permitir que com ele se pratique outro ato libidinoso" (CP, art. 213, caput). O estupro, consumado ou tentado, em qualquer de suas figuras (simples ou qualificadas), é crime hediondo

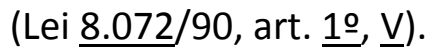

A Lei $\underline{12.015} / 2009$ transformou o delito de estupro em crime comum, assim, o sujeito ativo pode ser qualquer pessoa (homem ou mulher), uma vez que o tipo penal não mais exige nenhuma qualidade especial do agente, assim, é possível que haja estupro cometido por homem contra mulher, homem contra homem, mulher contra homem e mulher contra mulher.

Sujeito passivo é qualquer pessoa (homem ou mulher), independentemente de suas qualidades (honesta ou desonesta, recatada ou promíscua, virgem ou não, casada ou solteira, velha ou jovem). Entretanto, tratando-se de vítimas vulneráveis, o crime será o de estupro de vulnerável ( $\underline{\mathrm{CP}}$, art. 217-A).

O Estatuto da Criança e do Adolescente (ECA, Lei 8069/90) traz em seu artigo 241 que fotografar ou publicar cenas de sexo explícito ou pornográfica que envolva crianças ou adolescentes está sujeito a pena de seis meses a dois anos de retenção e multa. “...falta maior rigor para a punição, pois, ao expor uma imagem dessa natureza na Internet, veículo este que alcança o mundo todo em uma velocidade assustadora, o dano causado ganha uma proporção tão grande que a pena imposta torna-se irrisória" (SILVA, 2004).

A chefe da divisão de Direitos Humanos da Polícia Federal diz que as empresas provedoras de acesso à internet precisam cooperar mais com as autoridades: "Alguns provedores ainda não tem esse arquivo para nos fornecer e, muitas vezes, o que acontece é a dificuldade em obtermos esses dados que estão cadastrados com as empresas", afirma Leila Vidal, delegada da Polícia Federal - Reportagem do Jornal Hoje (27/março/2009).

A Polícia Federal defende a aprovação de uma lei que obrigue os provedores a monitorar melhor a navegação na internet, mas reforça que esse controle não dispensa outros cuidados pois a proteção das crianças e adolescentes cabe à todos e o que realmente está em falta é a sensibilização dos familiares e o não medo de denunciar o abuso.

O governo dos Estados Unidos em 2009 investiu duramente no combate à pedofilia no Brasil; sua polícia federal (FBI) treinou 1,4 mil brasileiros da área jurídica em investigações contra esse tipo de crime. "Ainda que os países se sintam ameaçados em sua soberania, pela cessão de espaço à cooperação internacional, não se pode conceber o combate aos crimes cibernéticos sem essa abertura. Acordos, tratados e convenções devem ser firmados sob a égide de um objetivo superior aos propósitos individuais, sob pena da perda real da soberania para a comunidade criminal." HERNÁNDEZ, José Manuel Lavers (27/janeiro/2011).

\section{MEDIDAS ATUAIS AINDA EM ANÁLISE}


O relator da Comissão Parlamentar de Inquérito (CPI) dos Crimes Cibernéticos, deputado Esperidião Amin (PP-SC), apresentou No dia 31 de março de 2016 9quinta-feira) o texto final do parecer no qual sugere 19 medidas para combater delitos praticados pela internet.

Um pedido de vista coletivo adiou, por duas sessões, o início da discussão do texto. A expectativa é que a votação da matéria ocorra entre os dias 12 e 13 de abril - prazo final de funcionamento da CPI. Entre as sugestões do relator estão: alterar o Marco Civil da Internet $(\mathrm{MCl}$ Lei $12.965 / 14)$ para facilitar a identificação de criminosos virtuais; tornar hediondos os crimes ligados à pedofilia; e criminalizar qualquer tipo de invasão de dispositivo informático (computadores, tablets, celulares e similares).

O relatório final propõe, por exemplo, por meio de projeto de lei, a inclusão do endereço IP no conjunto de informações cadastrais dos usuários de internet. "A rápida identificação de agressores é de fundamental importância para limitar os danos causados à vítima", observou Amin. O relator explicou que, pela atual sistemática do Marco Civil da Internet, a identificação do usuário se dá em três etapas, o que dificulta a identificação do autor do delito. Ainda contra o anonimato na rede, ele sugere a adoção do protocolo de internet IPv6, o que, segundo Amin, contribuiria para resolver essa questão.

É proposto um projeto de lei para alterar o Marco Civil da Internet e responsabilizar subsidiariamente sites e aplicativos de internet nos casos em que os conteúdos que atentarem contra a honra não seja removido em até 48 horas.

Segundo o relator, a CPI constatou ainda carências na estrutura das policias Federal e estaduais para o combate dos crimes cibernéticos. Para tentar reverter essa situação, o relatório sugere, por meio de projeto de lei ordinária, a aplicação de $10 \%$ das receitas do Fistel (Fundo de Fiscalização das Telecomunicações) para financiar o aparelhamento dessas polícias.

\section{CONCLUSÃO}

As vítimas de abuso sexual podem pensar que estão sendo castigados por terem feito algo de errado e então por isso sofreram esse tipo de violência, muitos pensam até em cometer suicídio. Cabe aos pais, familiares, conhecidos, educadores e profissionais de saúde a identificação precoce e no tratamento a pedofilia. Uma das atitudes a serem tomadas é a atenção ao comportamento, forma de agir e pensar dos adolescentes e crianças.

Compreender o resultado devastador do abuso sexual em idade precoce é essencial para reforça a necessidade de punição e intervenção que evitam novas ações de novos pedófilos que possam surgir.

Deve-se existir uma ponte entre Estado e família, pois ambos devem "caminhar de mãos dadas" contra esse crime tão perverso, de um lado o Estado agindo de acordo com os avanços do crime, fazendo com que a legislação acompanhe-o tendo assim, um progresso eficaz.

Do outro lado cabe às famílias impor limites às crianças e adolescentes, procurando sempre instrui-los de forma correta, sem pressões, opressões ou algo do tipo, mas sim, com diálogos calmos e claros para boa compreensão dos mesmos.

\section{REFERÊNCIAS}

ARAÚJO, Naira (2004). Abuso e exploração sexual contra crianças e adolescentes.

\section{AZEVEDO; GUERRA, (1998, p.33). Violência Domestica Contra Criança e Adolescente.}

COUTINHO, Isadora Caroline Coelho. Pedofilia na Era Digital. 
CASTRO, Joelíria Vey e BULAWSKI, Cláudio Maldaner. O perfil do pedófilo: Uma abordagem da realidade brasileira.

ESBER, Karen Michel. Entenda as diferenças entre pedofilia e violência sexual (10/agosto/2010). HERNÁNDEZ , José Manuel Lavers. Os crimes de pedofilia na rede mundial de computadores (27) janeiro/2011).

Kaplan e Sadock (1990, p.379). Compêndio de Psiquiatria Dinâmica.

NOGUEIRA, Sandro D'Amato. Pedofilia pela Internet - O lado negro da Web (20/junho/2003).

SILVA, Anna Paula Costa. Pedofilia na Internet - inocência roubada virtualmente (29/junho /2004).

TRINDADE e BREIER). Reportagem do Jornal Hoje (27/março/2009). Maioria dos casos de pedofilia começam pela Internet. 